\title{
Pharmacognostic, Physicochemical and Anti-Oxidant Screening of Solenostemma Argel's Leaf Extract
}

\author{
Mehad Mustafa Adam Khamiss ${ }^{1}$ \\ ${ }^{1}$ Department of Chemistry, \\ Faculty of Science, Mewar University, \\ Gangrar, Chittorgarh (Raj.) INDIA
}

\begin{abstract}
The present work deals with the identification of new approach towards the lead generation in medicinal chemistry and authenticating the reports present on the use of this Sudanese medicinal plant Solenostemma argel in the tribal region of Sudan. The pharmacognostic screening showed its physical and chemical composition with identification of active ingredients. The antioxidant activity was carried out by DPPH and nitric oxide scavenging method. In which ethanolic leaf extract showed prominent response which may be due to the promising presence of flavonoids and related poly phenolic compounds in it.
\end{abstract}

Keywords:- Solenostemma Argel, Antioxidant, Pharmacognostic, Flavonoids.

\section{INTRODUCTION}

Nature is the most faithful and non-demanding friend to mankind. It provides all things which are essential for the healthy life of human being i.e. food, shelter, cloths, and medicine. The majority of things provided by a key component of nature that is plant kingdom. In terms of medicine, it is a very important and precious weapon against pathogens. There are a variety of plants with strong response against a number of disease like cough, cold, fiver, diarrhea, dysentery, malaria, asthama[1], antibiotics, immunosuppressant, anticancer drugs[2], rheumatism[3], blood purifier[4], antioxidant[5],antileprotic[6] and many more reports on different diseases and their natural products treatments are present in literature[7]. Some plants also serve as probioactive ingredients for manufacturing of many crucial drugs[2]. Plants also presents themselves as precursors of model drugs production of new synthetic compounds[8] example erythroxylum coca has served as model for the synthesis of procaine[9] . it is a well proven fact that due to the priceless importance of medicinal plants, i.e. their easy availability, cost effectiveness and less or zero side effects, a large population of the world dependent on them[10].

Widely diversified climates of Sudan showcase itself as a game player for its richness in vegetation and flora. It is estimated that more than 3156 plants species are present there and out of them many are used in traditional medicine. Solenostemma Argel is a desert plant of Sudan and used in traditional medicines and in agriculture as antiinflammatory, Antimicrobial, Analgesic activity, antidiabetic, Toxicity, Insecticidal, Nematicidal etc.[11]

\author{
Prakash C. Choudhary* \\ * Department of Chemistry, \\ Faculty of Science, Mewar University, Gangrar, Chittorgarh \\ (Raj.) INDIA
}

Free radicals and reactive oxygen species (ROS) are responsible for many disorders in human which are generated due to imbalance in between formation and neutralization of peroxidents during oxidative stress. They cause oxidative damage to lipids, proteins and DNA leading to many chronic diseases i.e. cancer, aging etc. in human body, enzymes like superoxide dismutase, glutathioneperoxidase, catalase etc are generated to reduce the adverse effects of these free radicals. But due to less effectiveness of these enzymes and more generation of free radicals lead to cause diseases. Therefore it is very necessary to identify such species which serve as super antioxidant effect to support human to fight against such chronic diseases[12].

On this overview, we focused our search in this direction of finding new outcome and proving facts present on $S$. argel and use of leafs extract for evaluation of antioxidant activity at it is a rich source of saponin, flavonoids and glycosides.

\section{MATERIALS AND METHODS}

\section{A. Plant Material:}

The $S$. argel plant sample was collected from remote area of north Sudan and were authenticated by Dr. C. Prabhakar Raju, Taxonomist, Department of Botany, Faculty of Science, S.S.B.N. College Anantapur, AP (India) and herbarium voucher were also deposited in the departmental herbarium by reference no. S.S.B.N.SA/PLA/2016/1014.

\section{B. Chemicals:}

All chemicals and solvents (Lab Grade) are purchased from Sigma Aldrich Co USA, SD Fine Chem and used as such without further purification.

\section{PHARMACOGNOSTIC SCREENING}

Preparation of Crude Drug for extraction: The Plant S. Argel leaves were washed thrice with distilled water and then dried under shade. After proper drying they were coarsely powdered by mechanical grinder. The powder was sieved through 40 mesh sieve and stored in an air tight container for further use.

\section{A. Physico-chemical screening:}

The finely dried and sieved power (raw drug) was subjected to determine various parameter i.e. moisture, $\mathrm{pH}$, total ash, water soluble ash, acid sulphated ash, sulphated 
ash, solubility (in water and alcohol), crude fiber content, foaming index etc using a well-documented procedure[1315]. The results were tabulated in table -1 . Extractive value determination in either solvent (water / alcohol) was done by method mentioned in literature[13-15]. The percentage of soluble extractive value was also calculated and mention in table -1 .

Determination of extractive Value: 50 gm of coarsely powdered and sieved air dried leaves were macerated with
$100 \mathrm{ml}$ of solvent (ethanol and water) in a closed flask for 24 hour, rapidly vibrating customarily for six hours and permitted to stand for eighteen hours. It was then sieven swiftly taking precaution against loss of alcohol and the strain was volatilized to dryness in tarred flat bottomed superficial dish, dried at $105^{\circ} \mathrm{C}$ and weighed.

The percentage of alcohol soluble extractive was measured with reference to the air dried drug[15].

\begin{tabular}{|c|c|c|c|}
\hline S.N & & Parameters & Percentage $(\% \mathrm{w} / \mathrm{w})$ \\
\hline 1 & & $\mathrm{pH}$ & $7.5 \pm 0.5$ \\
\hline 2 & & Total ash & $5.8 \pm 0.3$ \\
\hline 3 & & Acid insoluble ash & $4.23 \pm 0.4$ \\
\hline 4 & & Water soluble ash & $4.55 \pm 0.5$ \\
\hline 5 & & Sulphated ash & $5.34 \pm 0.3$ \\
\hline \multirow{2}{*}{6} & \multirow{2}{*}{ Solubility } & Water soluble extractive & $18.5 \pm 0.4$ \\
\hline & & Alcohol soluble extractive & $9.6 \pm 0.4$ \\
\hline 7 & & Crude fiber content & $4.56 \pm 0.2$ \\
\hline 8 & & Loss on drying & $7.83 \pm 0.6$ \\
\hline 9 & & Foaming index & Less than 100 \\
\hline
\end{tabular}

Table 1:- Determination of ash values of selected medicinal plants

\section{B. Qualitative phyto-chemical evolution:}

Phyto-chemical screening was carried out for identification of active ingredients present in various extracts. The extraction was carried out using literature method[12]. In this method the collected, cleaned and pulverized leaves of Solenostemma argel were used for the extraction purpose. 500gm of powdered leaves were evenly loaded in the soxhlet apparatus. It was then extracted with solvents with varying polarity order from non-polar to polar constantly. The extraction method used was incessant hot percolation and carried out with various solvents, for 72 hrs. The extracts were concentrated by vacuum distillation to till complete dryness. Then they were cooled and placed in a desiccator for complete dryness. The dried extracts were packed in airtight containers and used for further studies. Then these fractions were evaluated for presence of different components by applying qualitative primary test methods followed by confirmatory tests for their particular fictional group. The results are tabulated in table- 2 .

\begin{tabular}{|c|c|c|c|c|c|}
\hline S. No & Secondary metabolites & n-Hexane & Ethyl acetate & Ethanol & Aqueous \\
\hline 1 & Sterols & + & - & + & + \\
\hline 2 & Fixed olis and fats & + & + & + & ++ \\
\hline 3 & Protein and amino acids & - & + & + & + \\
\hline 4 & Tri terpinoids and saponins & + & + & + \\
\hline 5 & Alkaloids & + & + & + & + \\
\hline 6 & Carbohydrates & + & + & + \\
\hline 7 & Flavonoids & + & + & + \\
\hline 8 & Tannins & + & + & + \\
\hline 9 & Glycosides & + & + & + \\
\hline 10 & Phenolic comp and Polyphenols & + & + & + \\
\hline
\end{tabular}

+ : present; ++ : present at high level; - : absent

Table 2:- Phytochemical studies

The fluorescence analysis: the fluorescence analysis of the powdered raw drug was carried out under visible white and UV light (short $\lambda-254 \mathrm{~nm}$ and long $\lambda$ - 365nm) in different solvent system which were used for extraction according to increasing polarity using well reported method in literature[16-17]. In this procedure $0.5 \mathrm{gm}$ of crude powder was mixed with $5 \mathrm{~mL}$ different solvent systems (acids or bases) and left for $12 \mathrm{Hr}$. then it was filtered and filtrate was examined for fluorescence analysis. The results are presented in table -3 . 
ISSN No:-2456-2165

\begin{tabular}{|c|c|c|c|c|}
\hline S. No & Reagents & Day light & Short UV & LongUV(365nm) \\
\hline 1 & Powdered Leaf & Light green & Dark green & green \\
\hline 2 & Powder $+1 \mathrm{~N} \mathrm{HCl}$ & Green & Light green & Light green \\
\hline 3 & Powder $+1 \mathrm{~N} \mathrm{NaOH}$ & Light green & Red & Light green \\
\hline 4 & Powder $+50 \% \mathrm{HCl}$ & Light green & Fluorescent green & Fluorescent green \\
\hline 5 & Powder $+50 \% \mathrm{H}_{2} \mathrm{SO}_{4}$ & Light green & Dark green & Dark green \\
\hline 6 & Powder $+50 \% \mathrm{HNO}_{3}$ & Dark brown & Brown & Reddish brown \\
\hline 7 & Powder $+\mathrm{Methanol}$ & Light green & green & Light green \\
\hline 8 & Powder + Methanol $+1 \mathrm{~N} \mathrm{NaOH}$ & Light green & brown & Light green \\
\hline
\end{tabular}

Table 3:- Fluorescence analysis of powder

\begin{tabular}{|c|c|c|c|c|}
\hline \multirow{2}{*}{ S. No } & Extracts & Day light & Uhort (254nm) & Long (365 nm) \\
\cline { 3 - 5 } & & & green & Dark green \\
\hline 1 & n-Hexane & Light green & Brown & Dark green \\
\hline 3 & Chloroform & Reddish brown & Light green & Light green \\
\hline 4 & Ethyl acetate & Yellowish green & Orangish green & green \\
\hline
\end{tabular}

Table 4:- Fluorescence analysis of various extracts

\section{PHARMACOLOGICAL STUDY}

\section{A. In-Vitro Efficacy Evaluation:}

Dried leaf's ethanolic extract was dissolved in the respective solvents at the stock of concentration of 1 $\mathrm{mg} / \mathrm{ml}$. The suitable preparation of the stock solutions were made and used for the in vitro antioxidant assays.

Diphenylpicrylhydrazyl radical assay method (DPPH method) : The protocol used for this assay is well reported by Brand-Williams W.[18] We used this method with some modifications as per requirement of protocol. In which 50 $\mu \mathrm{L}$ of leaf extract was taken in an universal bottle with varying concentration from $50 \mathrm{ppm}$ to $400 \mathrm{ppm}$ and $1 \mathrm{~mL}$ (W/V) (8 mg / $100 \mathrm{~mL}$ of ethanol) DPPH solution was added to sample and blank. It was kept at room temperature for $30 \mathrm{~min}$. for incubation. During this time the DPPH radical is scavenged, the color of the reaction mixture changed to yellow form purple indicated the decrease in absorbance at wavelength $517 \mathrm{~nm}$. So after incubation period the absorbance was taken at $517 \mathrm{~nm}$ by UV-1800 spectrophotometer, Shimadzu, Japan. Scavenging capacity was figuring by tracking the decrease in absorbance at 517 $\mathrm{nm}$. The percentage inhibition was calculated against blank. The results were tabulated in table -4 .
Percentage Inhibition was measured by using formula; Inhibition (\%)

$$
=\frac{(\text { Absorbance of Control }- \text { Absorbance of Test })}{\text { Absorbance of Control }} \times 100
$$

B. Nitric oxide radical scavenging activity:

In this method sodium nitroprusside (SNP) solution is used which generate nitric oxide spontaneously at physiological $\mathrm{pH}$ and when this oxide interacts with oxygen produces nitrite ions, which are quantified and determined according to Griess reaction[19]. The reaction mixture (final volume-3 $\mathrm{ml}$ ) of various concentration of drug containing sodium nitroprusside $(10 \mathrm{mM})$ in $0.5 \mathrm{M}$ phosphate-buffer ( $\mathrm{pH}-7.4)$ saline were incubated at $25^{\circ} \mathrm{C}$ for $150 \mathrm{~min}$. then $0.5 \mathrm{~mL}$ Griess reagent was added. The absorbance of purple chromophore formed by the diazotization of nitrite ion with sulfanilamide and subsequent coupling with $\alpha$-naphthyl-ethylenediamine were measured by spectrophotometrically at $546 \mathrm{~nm}$. Ascorbic acid was used as control sample. Percent inhibition was calculated by comparing the absorbance values of test samples as per the formula:

$$
\text { Inhibition }(\%)=\frac{(\text { Control }- \text { Test })}{\text { Control }} \times 10
$$


ISSN No:-2456-2165

\begin{tabular}{|c|c|c|c|}
\hline Extracts & Conc. Of extracts in ppm & $\begin{array}{c}\% \text { of DPPH free radical } \\
\text { activity }\end{array}$ & $\begin{array}{c}\% \text { of Nitric oxide radical } \\
\text { activity }\end{array}$ \\
\hline \multirow{5}{*}{ n-Hexane } & 50 & $45 \%$ & $39 \%$ \\
\hline & 100 & $58 \%$ & $48 \%$ \\
\hline & 150 & $60 \%$ & $52 \%$ \\
\hline & 200 & $65 \%$ & $57 \%$ \\
\hline & 400 & $68 \%$ & $63 \%$ \\
\hline \multirow{5}{*}{ Ethyl acetate } & 50 & $55 \%$ & $47 \%$ \\
\hline & 100 & $58 \%$ & $52 \%$ \\
\hline & 150 & $65 \%$ & $59 \%$ \\
\hline & 200 & $70 \%$ & $63 \%$ \\
\hline & 400 & $75 \%$ & $68 \%$ \\
\hline \multirow{5}{*}{ ethanol } & 50 & $65 \%$ & $60 \%$ \\
\hline & 100 & $68 \%$ & $63 \%$ \\
\hline & 150 & $70 \%$ & $68 \%$ \\
\hline & 200 & $75 \%$ & $71 \%$ \\
\hline & 400 & $82 \%$ & $79 \%$ \\
\hline \multirow{5}{*}{ Aqueous } & 50 & $55 \%$ & $52 \%$ \\
\hline & 100 & $58 \%$ & $57 \%$ \\
\hline & 150 & $65 \%$ & $61 \%$ \\
\hline & 200 & $68 \%$ & $69 \%$ \\
\hline & 400 & $70 \%$ & $72 \%$ \\
\hline \multirow{5}{*}{ Ascorbic acid Standerd } & 50 & - & $68 \%$ \\
\hline & 100 & - & $73 \%$ \\
\hline & 150 & - & $77 \%$ \\
\hline & 200 & - & $83 \%$ \\
\hline & 400 & - & $89 \%$ \\
\hline
\end{tabular}

Table 5:- Antioxidant activity of bark solvent extracts based on their polarity

\section{RESULT AND DISCUSSION}

In this present study, relatively all physical, chemical and biological parameters were studied to find a concentrated conclusion. All the results mentioned in different tables showed specific results which are briefed below.

Physico chemical screening: this analysis of the powdered leaves of $\mathrm{S}$. argel showed that the moisture content was $7.8 \%$ and total solid was $92.20 \%$, total ash was $5.8 \%$, in which water soluble ash was $4.5 \%$ and acid insoluble ash was $4.2 \%$, and sulphated ash was $5.3 \%$. The extractive valve of crude drug was as water soluble $18.5 \%$ and alcohol soluble was $9.6 \%$. The crude fiber content was $4.5 \%$. Its foaming index was $<100$ recorded.

Qualitative screening of extracts revealed the presence of alkaloids and carbohydrates in all extracts. Spot test was found to be positive revealing the presence of fixed oils. Phenolic compounds and Tannins were found to be present in all extracts. Tests for proteins were also found to be positive indicating the presence of proteins and amino acids. Tests for Alkaloids were found to be positive in extracts of Solenostemma argel whereas tests for carbohydrates and glycosides were found to be positive for all other three extracts. Tests for tannins and phenolic compounds were found to be positive for all extracts.

The screening of Solenostemma argel extracts of different solvents was performed to test for the presence of steroids, triterpenes, saponins, alkaloids, carbohydrates, flavonoids, tannins, glycosides and results were tabulated.

The fluorescence results were very specific with raw drug as well as with different extracts as mentioned in table $-3 \& 4$. The results showed very specific color change pattern with strong dark colors after treatment with various reagents or solvent extractions. It may be due to characteristic salts or complexes formed with alkaloids or flavonoids present in that particular fraction. This technique may be used in the identification of authentic samples and recognizing adulterants. 


\section{A. Evaluation of In Vitro Efficacy:}

D DPPH Radical Scavenging Activity of Extracts:

Different fractions of plant extract for free radicals of 1, 1-diphenyl 1-2-picryl-hydrazyl (DPPH) showed remarkable scavenging activities in Table 5. Ethanolic extract showed the highest scavenging activity followed by Ethyl acetate. DPPH scavenging activity was significantly correlated with phenolic compounds and flavonoids present in different extracts.

Nitric oxide radical scavenging activity:

As results presented in table-5 the different extracts caused a low dose dependent inhibition of nitric oxide. The best results were showed by ethanolic extract with followed by ethyl acetate extract. It may be due to the solvents polarity which resulted in extraction of majority of polyphenolic compounds or flavonoids and terpinoids or active polar entity. The results of both of solvent extractions were quite comparative with slandered dose of ascorbic acid.

\section{CONCLUSION}

Phytochemicals present in the different extracts of Leaves of Solenostemma argel was identified. Among the extracts ethanolic extract has highest anti-oxidant property when compared to other extracts. In the present study it was found that Solenostemma argel leaves ethanolic extract has an excellent antioxidant activity. Therefore the future studies should be aimed to exploit this plant to be used as one of the best medicinal plant is controlling pathogenic bacteria. However further investigations are needed for isolation and purification of key ingredients of this plant for prominent use of it as drug candidate for human being.

\section{REFERENCES}

[1]. Rakotoarivelo N. H., Rakotoarivony F., Ramarosandratana A. V., Jeannoda V. H., Kuhlman A. R., Randrianasolo A. and Bussmann R. W.; J Ethnobiol Ethnomed; 2015,11:68.

[2]. Katiyar C., Gupta A., Kanjilal S., and Katiyar S.; Ayu. ; 2012, 33(1), 10-19.

[3]. Barkathullah, Ibrar M., Jelani G., Rehamnullah, Ehsan M.; Int. J. Biosciences; 2012, 2,46-56.

[4]. Balakrishnan, S.; Natarajan, B.; Arumugam, B.; Hariram, B. V.; Pharmacon. J. ;2011, 3(19), 13-18.

[5]. Borris, R.P.; J. Ethnopharmacol; 1996, 51, 29-38.

[6]. Evans, W. C. Plants in medicine: the origins of pharmacognosy. In: Tease and Evans's Pharmacognosy.15th ed. W. B. Saunders, London, U. K. 2002, pp: $3-4$.

[7]. Evans, W. C., Pharmacognosy. 15th ed. English Language Book, Society Baillere Tindall, Oxford University Press. 2002.

[8]. Padmavathy J., and Saravanan D.; J Pharmacol; 2017, 12, 151-161.

[9]. Tsuchiya H.; Molecules; 2017, 22, 1369.

[10]. Farnsworth N.R. and Soejarto D.D., The Conservation of Medicinal Plants. Cambridge University Press, Cambridge, UK, 1991, 25-51.
[11]. Teia F. K. F.; J. Ayu. Herb. Med. ;2018, 4(2), 99-101

[12]. Gangwar M, Gautam M K, Sharma A K, Tripathi Y B, Goel R K, Nath G.; Scientific World J.; 2014, 1,19.

[13]. Ministry of Health and Family Welfare.Ayurvedic Pharmacopoeia of India. 1st ed. New Delhi: Government of India, Ministry of $\mathrm{H}$ and $\mathrm{FW}$, Department of Indian System of Medicine \& Homoeopathy; 2001,1 (1) ,14, 143.

[14]. Siddiqua A, Premakumari K B, Sultana R, Vithya, Savitha; Int. J. Chemtech Res ; 2010, 2(1), 205-208.

[15]. Kyari MZ; Int. Agrophysics; 2008, 22, 139-142

[16]. Madhav NVS, Upadhyaya K, Bisht A; Int. J. Pharm. Pharm. Sci.; 2011, 3, 235-238

[17]. Shukla SH, Mistry, HA, Patel VG, Jogi BV.; Pharma sci. monit.; 2010, 1(1), 90-102

[18]. W. Brand-Williams, M. E. Cuvelier and C. Berset; LWT-Food Sci Technol; 1995, 28, 25-30.

[19]. Green LC, Wagner DA, Glogowski J, Skipper PL, Wishnok JS, Tannenbaum SR.; Anal Biochem.; 1982,126(1),131-8. 